\title{
Application of microstructure classification for the assessment of the variability of geological-engineering and pore space properties in clay soils
}

https://doi.org/10.1515/geo-2019-0019

Received Jun 13, 2018; accepted Apr 06, 2019

\begin{abstract}
The performed investigations were focused on analysing the variability of geological-engineering properties in clay soils from central-eastern Europe with regard to microstructures. Thirty-nine soils differing in origin, lithology and microstructure type were selected for analysis. Results of studies on lithological and physical and mechanical parameters were analysed, coupled with quantitative microstructural parameters based on microstructure images. The relationships between lithological, physical and mechanical and pore space parameters were determined with regard to microstructure types. Sediment origin and diagenesis, and soil microstructure and pore space parameters had influence on the geological-engineering properties. Such approach allows for predicting engineering parameters based on soil microstructure types and their pore space parameters.
\end{abstract}

Keywords: clay soils, SEM, microstructure, pore space, physical and mechanical properties, correlation

\section{Introduction}

Studies of the structure in sedimentary rocks may facilitate the recognition and interpretation of their origin, post-sedimentary alteration, as well as engineering properties. In engineering geology, the structure of clay soils (microstructure in studies based on scanning electron microscopy - SEM) is defined as the sum of three compo-

\footnotetext{
^Corresponding Author: Jerzy Trzciński: Wrocław Research Centre EIT+, Stabłowicka 147, 54-066 Wrocław, Poland; Email: jerzy.trzcinski@uw.edu.pl

Emilia Wójcik: Institute of Hydrogeology and Engineering Geology, Faculty of Geology, University of Warsaw, Żwirki i Wigury 93, 02-089 Warszawa, Poland
}

nents: 1) grain size and mineral composition, and the chemical composition of the solid, liquid and gas phases, 2) fabric, referring to the distribution, shape and dimensions of grains and particles, and the character of the pore space, and 3) forces acting at the contacts between grains and particles [1-3]. The qualitative and quantitative description of microstructure, similarly as other parameters, is crucial for characterising geological-engineering properties. Such complex approach to microstructural studies allows for a full recognition of soil behaviour, particularly in macro scale. This is extremely important in applied studies of soils that are used as foundation soil.

Structure studies using SEM have initiated new possibilities of its recognition. The first to use an electron microscope for the observation of clays were e.g. Eitel and Schusterius in 1939-1940. Their studies were focused only on determining the dimension and shapes of very fine particles of clay minerals [4]. A comprehensive overview of available techniques used in studies of soils at microscopic scale has been presented by Romero and Simms [5]. Among the numerous methods used earlier, these authors emphasise the particular usefulness of scanning electron microscopy in understanding the properties of geomaterials and their behaviour under various environmental factors.

Development of branches of engineering geology such as soil mechanics or soil science has raised interest in the structure of clay soils, particularly of clays. Some of the first reports were focused on issues related to theoretical models of the internal structure of clays [6-9]. Development of modern research techniques, including electron microscopy, initiated a subsequent stage of studies on the microstructure of clay soils [10-12]. Numerous monographs on the microstructure of clays and clay soils appeared as a result of long-term, dedicated studies $[1,4,13$, 14].

Numerous scientists devoted their research to microstructure and its influence on the geological-

๑ Open Access. (c) 2019 J. Trzciński and E. Wójcik, published by De Gruyter. 
engineering properties of lithologically and genetically variable clay soils. The literature in this topic is extremely rich [2, 15-37]. Detailed studies on glacial tills from Poland have evidenced crucial relationships between microstructural parameters and geological-engineering properties of these sediments [38-40]. Analysis of microstructure in clay soils was developed chiefly for practical applications, for example for the requirements of engineering geology and geotechnics [33, 41-43].

Most recent reports on microstructure include studies of various soils and geomaterials with regard to practical usage linked with geotechnics and road construction, which raises high interest among practitioners [e.g. 4449].

The first concepts of the internal structure of clays have been presented in the early 1900-ties [50]. More complex models were subsequently published. Terzaghi [6] proposed a system of single clay particles mutually contacting along a small area (point contacts) by sufficiently resistant bonds. Such spatial distribution was termed as a honeycomb structure. A modified and more complex model of Terzaghi's honeycomb structure for low-bearing and sensitive clays has been presented by Casagrande [8] Next, based on SEM studies, Aylmore and Quirk [51] proposed the term turbostratic arrangement or turbostratic structure for such system of clay particles. The turbostratic arrangement is formed of aggregates, in which clay particles contact parallel, along face-to-face (F-F) contacts. Such aggregates known as domains or stacks are arranged randomly in the structure.

Long-term SEM studies of structures on sedimentary rocks of various age, performed jointly by a team of scientists from the University of Warsaw and the Moscow State University, resulted in working out a classification scheme of microstructures in clay rocks [14, 52]. These investigations were summarised in the Atlas of the Microstructure of Clay Soils [1]. During our investigations, which include quantitative analysis and detailed quantitative characteristics of microstructures, we refer directly to this classification.

The presented report focuses on searching for a correlation between lithological features and physical and mechanical properties in clay soils with regard to selected types of microstructures included in the classification scheme mentioned above (Figure 1). It attempts to link microstructure and its properties with conditions of sediment formation and geological-engineering properties. This aim was accomplished by performing quantitative analysis of the microstructures, expanded statistical analysis, and detailed studies of the relationships between particular parameters.

\section{Material and methodology of the investigations}

A collection of archival data, published in the Atlas of the Microstructure of Clay Soils [1], was used in the investigations. The authors of the Atlas presented a classification of microstructures, innovative for the time of its publication and functioning till present, based on long-term studies. The publication contains also a complete list of geologicalengineering parameters and a qualitative characteristics of microstructure types with a set of SEM images for 86 soils varying in lithology and depositional environment. Genetically, the soils are represented by marine, lake, fluvial, and glacial sediments, and waste covers, whereas lithologically they mainly represent clays, and sandy and silty clays (Figure 2A). The soils derive from Poland - 35 samples, which accounts for $41 \%$, and from the European part of the former USSR - 51 samples, which accounts for $59 \%$. The age of the sediments ranges from the Precambrian to the Holocene.

Our investigations included all data from the Atlas, including lithological, mineralogical, physical and mechanical properties, and SEM images [1]. The following parameters were used for the preparation of a database with geological-engineering properties: grain size composition, content and composition of clay minerals, dry bulk density $\left(\rho_{d}\right)$, bulk density $(\rho)$, porosity $(n)$, specific surface area $(S)$, natural water content $(w)$, liquid limit $\left(w_{L}\right)$ and plastic limit $\left(w_{p}\right)$, plasticity index $\left(I_{P}\right)$, water saturation coefficient $\left(K_{w}\right)$, one-axial strength $(\sigma)$, maximum shear stress $\left(\tau_{\max }\right)$, minimum shear stress $\left(\tau_{\min }\right)$, resistance to cone penetration $(\mathrm{Pm})$, and propagation velocity of longitudinal ultrasonic waves $\left(V_{p}\right)$. The methodology of parameter tests is given in the Atlas $[53,54]$. Based on sets of SEM images of microstructures, a database - image library - was constructed.

Thirty-nine out of 86 samples were selected for detailed quantitative analysis of the microstructures. The main criterion for this selection was microstructure type and its abundance in the dataset. Three out of 5 basic types were selected, that is: 25 soil samples with a matrix microstructure, 8 soil samples with a honeycomb microstructure, and 6 soil samples with a laminar microstructure, which contributes to $45 \%$ of the entire dataset (Figure 2B).

Honeycomb and laminar microstructure types represent the most extreme members of microstructure classification, and the matrix microstructure is an intermediate member of the classification. Basic data, such as locality, depth, age or microstructure type have been compiled in Table 1. Most soils are from the European part of the for- 
Table 1: Basic properties of the clay soils studied (compilation based on data from Grabowska-Olszewska et al. 1984)

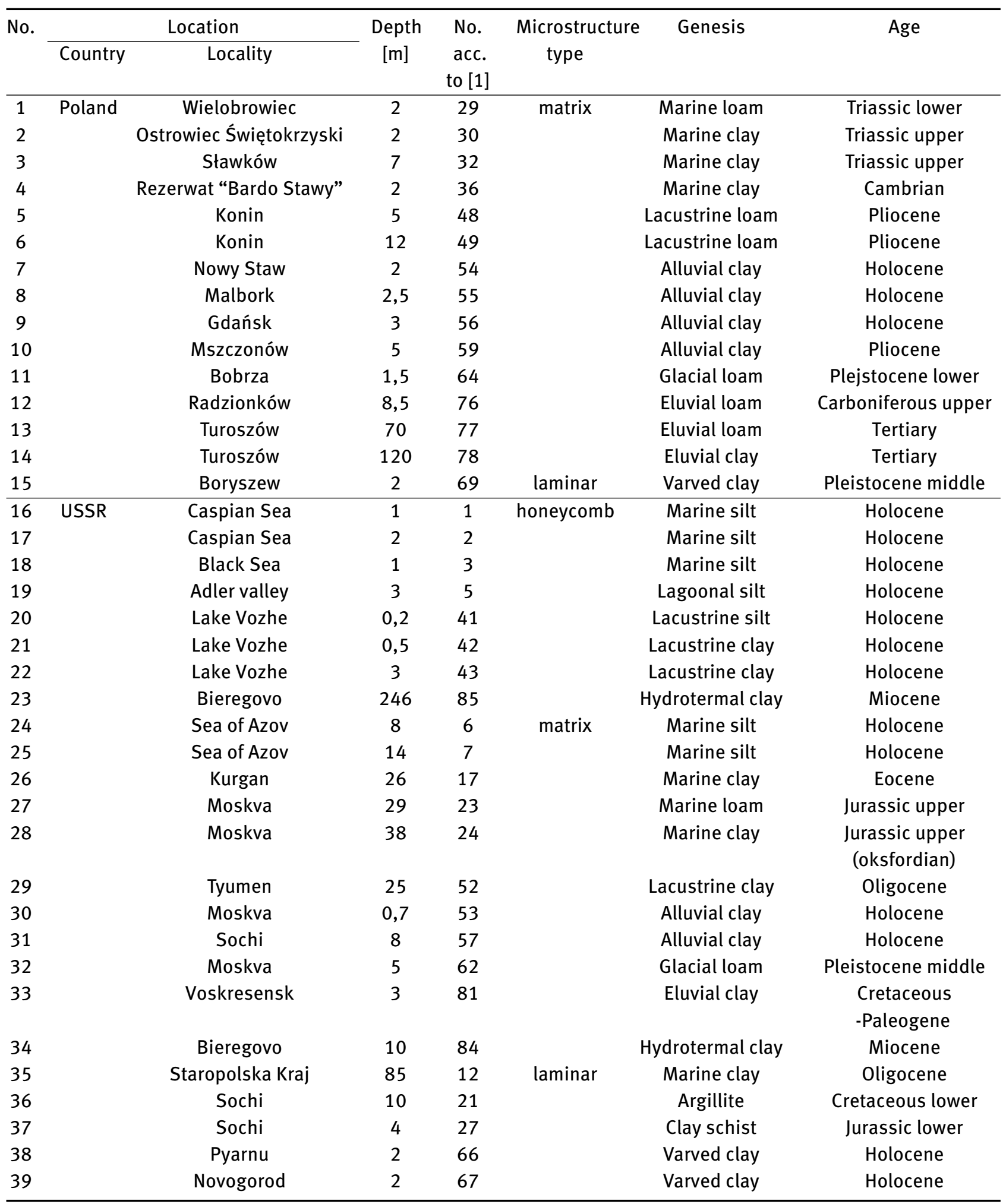


Table 2: Selected pore space parameters of the clay soils studied with regard to microstructural types. ${ }^{\star}$ - average

\begin{tabular}{|c|c|c|c|}
\hline \multirow[t]{2}{*}{ Parameters } & \multicolumn{3}{|c|}{ Type of microstructure } \\
\hline & Honeycomb & Matrix & Laminar \\
\hline \multirow{2}{*}{ Porosity n [\%] } & $16.4-34.0$ & $13.7-38.4$ & $10.9-33.7$ \\
\hline & $28.3^{*}$ & 22.5 & 24.1 \\
\hline \multirow[t]{2}{*}{ Number of pores $N \times 10^{3}$} & $90-2142$ & $293-7276$ & $632-3043$ \\
\hline & 906 & 1495 & 1537 \\
\hline \multirow[t]{2}{*}{ Average pores diameter $D_{a v}[\mu \mathrm{m}]$} & $1.1-9.7$ & $0.7-3.2$ & $0.8-2.0$ \\
\hline & 2.9 & 1.4 & 1.4 \\
\hline \multirow[t]{2}{*}{ Total pores area $S_{t} \times 10^{3}\left[\mu \mathrm{m}^{2}\right]$} & $5249-11180$ & $4324-12581$ & $3343-11020$ \\
\hline & 9190.1 & 7306.5 & 7769.4 \\
\hline \multirow[t]{2}{*}{ Average pores area $S_{a v}\left[\mu \mathrm{m}^{2}\right]$} & $4.5-111.8$ & $1.3-23.1$ & $1.3-14.0$ \\
\hline & 25.3 & 8.1 & 7.5 \\
\hline \multirow[t]{2}{*}{ Total pores perimeter $P_{t} \times 10^{3}[\mu \mathrm{m}]$} & $8863-21762$ & $8280-47110$ & $13785-29615$ \\
\hline & 15493 & 16499 & 18932 \\
\hline \multirow[t]{2}{*}{ Average pores perimeter $P_{a v}[\mu \mathrm{m}]$} & $10.1-116.6$ & $2.8-37.1$ & $7.6-22.4$ \\
\hline & 33.0 & 14.9 & 15.2 \\
\hline \multirow[t]{2}{*}{ Average form index of pores $K_{f a v}[-]$} & $0.45-0.63$ & $0.30-0.58$ & $0.33-0.49$ \\
\hline & 0.53 & 0.46 & 0.41 \\
\hline \multirow[t]{2}{*}{ Microstructure anisotropy index $K_{a}[\%]$} & $20.4-53.5$ & $34.1-76.7$ & $68.1-89.6$ \\
\hline & 37.7 & 49.9 & 76.2 \\
\hline \multirow[t]{2}{*}{ Mesopores $10<\varnothing<1000 \mu \mathrm{m}[\%]$} & $74.9-99.9$ & $35.5-92.2$ & $81.5-99.1$ \\
\hline & 91.6 & 89.0 & 93.6 \\
\hline \multirow[t]{2}{*}{ Micropores $0.1<\varnothing<10 \mu \mathrm{m}[\%]$} & $0.1-6.8$ & $0.3-19.4$ & $0.6-18.5$ \\
\hline & 2.5 & 4.2 & 6.3 \\
\hline \multirow[t]{2}{*}{ Fissure-like pores a/b>10 [\%] } & $0-4.6$ & $0-58.4$ & $8.0-56.0$ \\
\hline & 0.9 & 10.6 & 23.8 \\
\hline \multirow[t]{2}{*}{ Anisometric pores $1.5<a / b<10[\%]$} & $44.9-76.3$ & $37.3-95.6$ & $26.0-74.0$ \\
\hline & 64.3 & 68.7 & 60.7 \\
\hline \multirow[t]{2}{*}{ Isometric pores $\mathrm{a} / \mathrm{b}<1.5[\%]$} & $22.5-54.7$ & $2.7-47.9$ & $1.3-28.1$ \\
\hline & 34.7 & 20.5 & 15.6 \\
\hline
\end{tabular}

mer USSR (24 samples) and the rest are from Poland (15 samples).

Preparation of soil samples, published in the Atlas, for microstructural SEM studies was performed so that their natural structure was retained intact [1]. This condition is indispensable for a correct quantitative analysis and for obtaining real quantitative parameters of the microstructures [55-57]. The applied preparation procedure and the SEM images were used in the quantitative analysis. To achieve this, the microstructure images were scanned in high resolution and digital versions were prepared. The analysis was performed with application of specialised STIMAN - Structural Image Analysis - software [58]. This software was constructed for making quantitative microstructural investigations of soils using SEM images and statistical methods of image analysis. Based on this analysis, a series of parameters of the pore space was obtained: morphometric (diameter $D$, perimeter $P$, surface $S$ ) and geometric (form index of pores $K_{f}$, microstructure anisotropy index $K_{a}$ ). Histograms generated by the applied software were used to determine the contribution of isometric, anisometric and fissure-like pores, as well as micro- and mesopores. Table 2 presents the medium, maximal and minimal values of these parameters in relation to the analysed microstructure types.

As a result, three datasets were prepared: database with geological-engineering properties, database with SEM images, and database with quantitative microstructural parameters. The matrix of the correlation coefficient was obtained from the database with physical and mechanical parameters and the database with microstructural parameters; the most significant and most representative correlation relationships were selected from this matrix. 

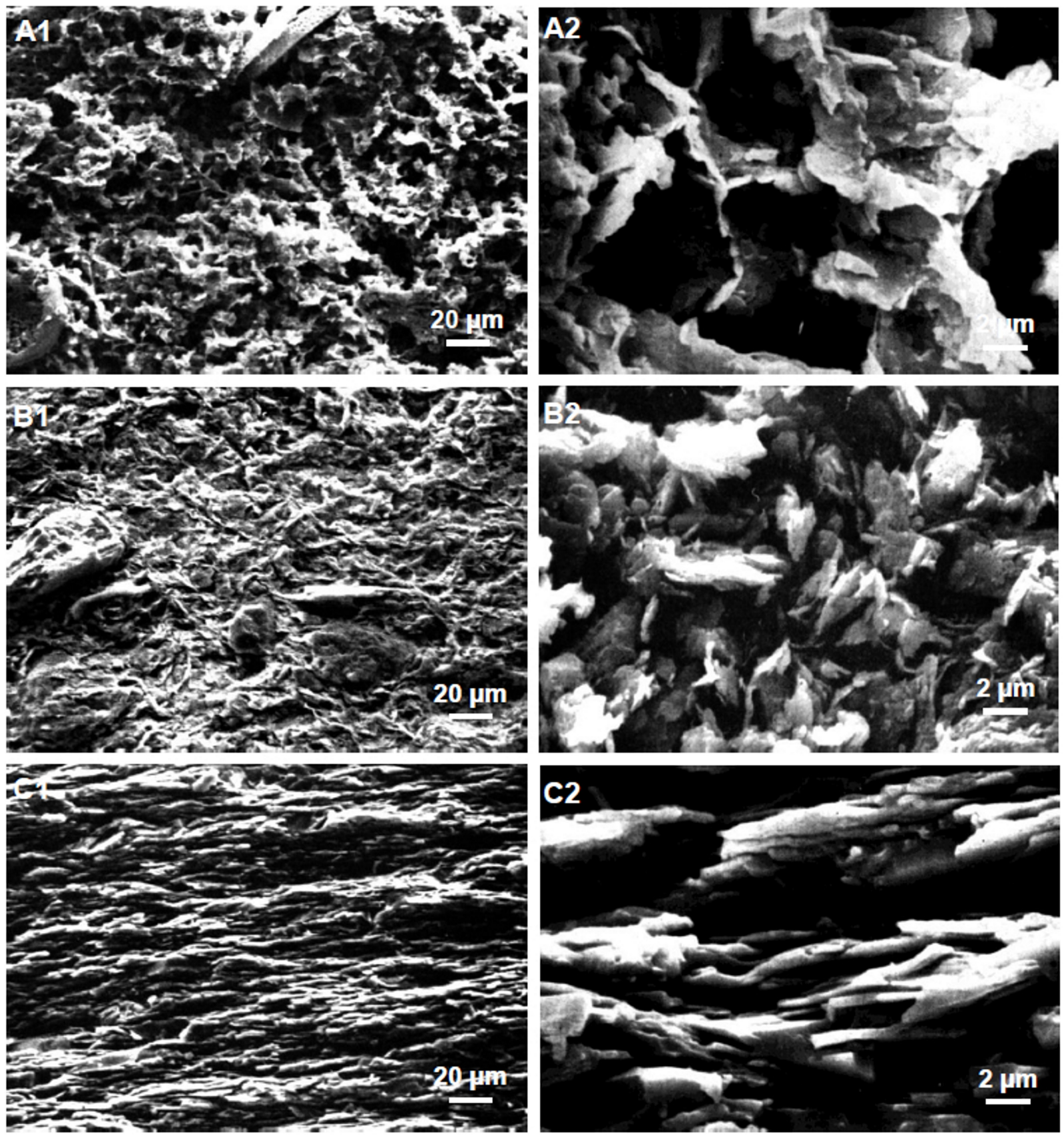

Figure 1: SEM images of three types microstructures for clay soils: A1, A2 - honeycomb (1*), B1, B2 - matrix (62*), C1, C2 - laminar (27*). A1, B1, C1 - magnification 500x, A2, B2, C2 - magnification 5000x. * - No. acc. to [1] in Table 1

\section{Variability of pore space parameters with regard to microstructures in clay soils}

Based on the quantitative analysis of microstructures, 23 parameters characterising the soil pore space were selected, from which a correlation matrix was constructed.
The charts present correlation relationships for high values of the correlation coefficient (Figure 3, Figure 4, Figure 5), whereas Table 2 presents a characteristics of selected parameters for the honeycomb, matrix, and laminar microstructures. Analysis of the parameters indicates that the number of pores and their total perimeter increase, whereas the medium diameter, medium perimeter, medium pore surface and total pore surface decrease from soils with a honeycomb microstructure to soils with a 


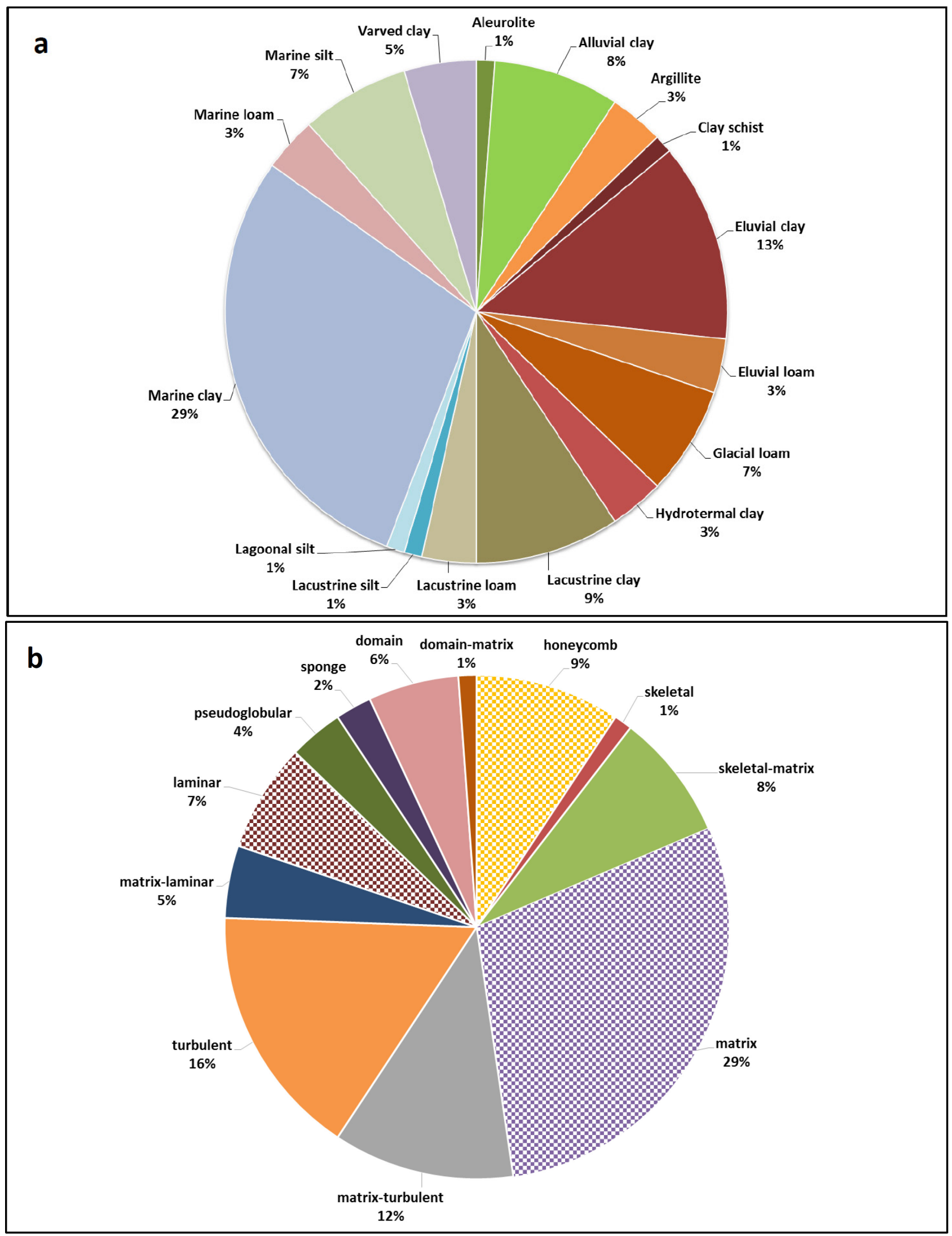

Figure 2: Classification of the clay soils studied: A - according to genetic types, B - according to microstructural types (compilation based on data from Grabowska-Olszewska et al. 1984) 


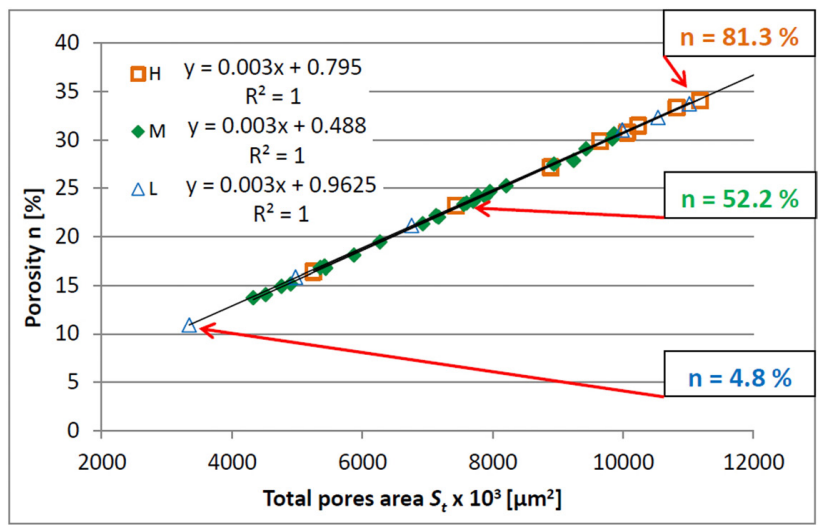

Figure 3: Chart showing the correlation between porosity $n$ and total pore surface $S_{t}$. See Figure 1 for the comparison of three types microstructures: $\mathrm{H}$ - honeycomb, $\mathrm{M}$ - matrix, $\mathrm{L}$ - laminar
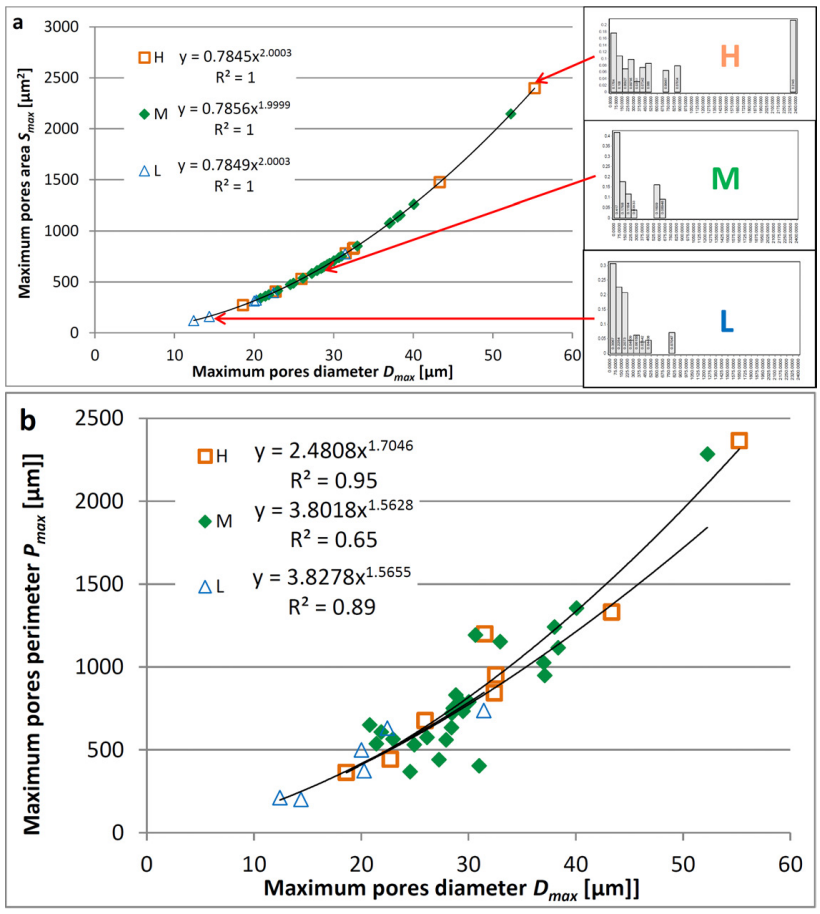

Figure 4: Chart showing the correlation between: $A$ - maximal pore area $S_{\max }$ to maximal pore diameter $D_{\max }$, B - maximal pore perimeter $P_{\max }$ to maximal pore diameter $D_{\max }$. See Figure 1 for the comparison of three types microstructures: $\mathrm{H}$ - honeycomb, $\mathrm{M}$ matrix, L - laminar

laminar microstructure. The value of the pore form coefficient $K_{f}$ is the lowest in soils with a laminar microstructure, which results in a high value of the anisotropy index $K_{a}$. Values of these parameters behave inversely in soils with a honeycomb microstructure, and intermediately in soils with a matrix microstructure. The content of meso- and micropores increases, and of fissure-like and anisometric
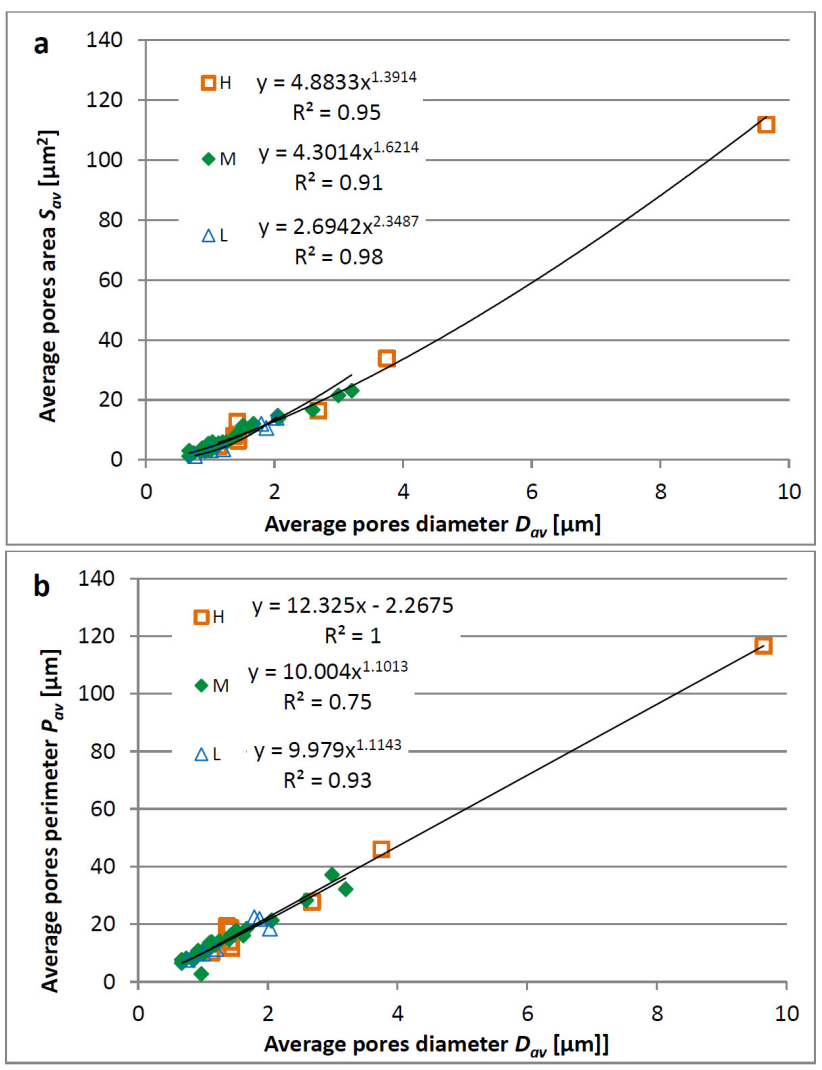

Figure 5: Chart showing the correlation between: $A$ - average pore area $S_{a v}$ to average pore diameter Dav, B - average pore perimeter Pav to average pore diameter $D_{a v}$ See Figure 1 for the comparison of three types microstructures: $\mathrm{H}$ - honeycomb, $\mathrm{M}$ - matrix, $\mathrm{L}-$ laminar

pores decreases from soils with a honeycomb microstructure to soils with a laminar microstructure.

The graph in Figure 3 presents another relationship with a high correlation coefficient equal to 1 , in which porosity directly depends on the total pore surface. Higher values of porosity and pore surface are observed in soils with a honeycomb microstructure, and lower values of these parameters are noted in soils with a matrix and laminar microstructure. There are some deviations from this trend, which may be explained by a variable degree of packing, and dimensions of grains and particles forming the microstructure. The porosity of soils with a honeycomb microstructure is low when the matrix is composed of tightly packed, very small particles and microaggregates. In turn, soils with a laminar microstructure are characterised by high porosity because they are built of large and loosely packed structural elements.

The next graph presents another relationship with a high correlation coefficient equal to 1 , in which the maximal pore diameter rises with the increase of maximal pore surface (Figure 4A). At first, the graph is non-linear, be- 
cause up to $35 \mu \mathrm{m}$ the pore diameter rises faster than the pore surface. Such relationship indicates that fissure-like and anisometric pores dominate in a diameter range between 10-35 $\mu \mathrm{m}$, because the increase of both parameters should be proportional for isometric pores. This is confirmed by the position of soils with a laminar microstructure in this part of the chart, with prevailing anisometric and fissure-like pore shapes. Above these diameter values, the increase of relationships is proportional, indicating isometric pore shapes. This is confirmed by the position of soils with a honeycomb microstructure, characterised by large and oval pores, in this part of the chart.

The relationship, in which increase of maximal pore perimeter causes increase of maximal pore diameter, has a similar course (Figure 4B). Such shape of the curve confirms conclusions drawn from the previous relationship (Figure 4A). The analysed graph shows another relationship, in which the smallest pores are anisometric or fissurelike in shape in soils with a laminar microstructure. In turn, for the highest diameter values, the pores are isometric and the soils have a honeycomb microstructure. The lowest correlation coefficient is observed in soils with a matrix microstructure, which indicates the highest dispersion of the results. Soils with this microstructure contain anisometric, fissure-like, and isometric pores, and their complex shapes are evidenced by high values of the maximal perimeter.

Graphs in Figure 5A and Figure 5B show similar relationships as in Figure 4 and represent the same average values for particular parameters. The significant increase of the average pore surface and pore perimeter is almost proportional with the increase of the average pore perimeter. Pore diameter rises slightly faster than pore surface and pore perimeter. Analysis of the graphs confirms the conclusions drawn for the maximal values of these parameters (Figure 4). The analysis indicates also that soils with a matrix microstructure contain pores with diameters in the range of 1-3 $\mu \mathrm{m}$; lower values of pore diameter were observed in soils with a laminar microstructure and higher values - in soils with a honeycomb microstructure. Such distribution of diameter values points to the degree of packing of the structural elements in the analysed types of microstructures. Soils with a honeycomb microstructure have larger and more isometric pores, and their structure is loosely packed. In turn, soils with a laminar microstructure have anisometric and fissure-like pores with smaller dimensions, and a more packed microstructure.

\section{Variability of geological-engineering properties with regard to microstructures of clay soils}

The compilation presents statistical parameters of soil physical and mechanical properties with regard to microstructure types (Table 3). The analysis indicates that soils with a honeycomb microstructure are characterised by the largest variability of water content, high porosity and lowest values of the dry bulk density. In soils with a matrix microstructure the water content and porosity vary in a much narrower range, and the dry bulk density attains intermediate values between those reached by soils with a honeycomb microstructure and soils with a laminar microstructure. Soils with a laminar microstructure are characterised by: a high content of the fraction below $1 \mu \mathrm{m}$, the lowest values of porosity and water content, and the dry bulk density reaching the highest values. The liquid limit $w_{L}$ and plastic limit $w_{P}$ attain the highest values in soils with a cell microstructure and the lowest values in soils with a laminar microstructure. The plasticity index $I_{P}$ attains the highest values in soils with a honeycomb microstructure and reaches similar values in soils with matrix and laminar microstructures. In consequence, soils with a honeycomb microstructure usually have a liquid texture, whereas soils with a matrix microstructure usually have a plastic or rarely semi-compact texture. In soils with a laminar microstructure, variability of texture is large and results from the variable degree of packing, which ranges from high to low values.

Based on the water content and the liquid limit, the degree of soil diagenesis may be assessed. The water content of the sediment directly after deposition varies between $1-1.5 w_{L}$, and decreases with time in result of diagenesis, for example compaction and cementation [59]. The degree of sediment diagenesis increases with a smaller ratio between the value of actual water content to the value of the liquid limit $w / w_{L}$ (Figure 6). This ratio is high in soils with a honeycomb microstructure and varies in a narrow range of values, whereas in soils with a matrix microstructure it is lower and varies in a wide range of values. Soils with a honeycomb microstructure are mainly young Holocene sediments of marine and lake origin. In such soils, sediment diagenesis is at an early stage. In turn, soils with a matrix microstructure represent various ages and are mostly of alluvial, glacial and lake origin, which causes that the values of the liquid limit are variable. Such soils have a very variable degree of diagenesis resulting not only from the age of 
Table 3: Selected physical-mechanical properties of the clay soils studied with regard to the microstructural types (compilation based on data from Grabowska-Olszewska et al. 1984). * - average

\begin{tabular}{|c|c|c|c|}
\hline Parameters/type of microstructure & Honeycomb & Matrix & Laminar \\
\hline \multirow{2}{*}{ Dry bulk density $\rho_{d}\left[\mathrm{~kg} / \mathrm{m}^{3} \times 10^{3}\right]$} & $1.14-1.89$ & $1.55-2.29$ & $1.74-2.6$ \\
\hline & $1.53^{\star}$ & 1.97 & 2.17 \\
\hline \multirow[t]{2}{*}{ Bulk density $\rho\left[\mathrm{kg} / \mathrm{m}^{3} \times 10^{3}\right]$} & $2.41-2.9$ & $2.55-2.93$ & $2.67-2.81$ \\
\hline & 2.71 & 2.73 & 2.73 \\
\hline \multirow{2}{*}{ Porosity $n[\%]$} & $46.3-90.4$ & $25.9-64.9$ & $4.8-60$ \\
\hline & 69.8 & 41.4 & 32.4 \\
\hline \multirow[t]{2}{*}{ Fraction $\varnothing<0,001 \mathrm{~mm}[\%]$} & $12-44$ & $5-56$ & $41-54$ \\
\hline & 31.9 & 28.5 & 47.3 \\
\hline \multirow[t]{2}{*}{ Montmorillonite [\%] } & $5-35$ & $5-100$ & $5-40$ \\
\hline & 13.3 & 38.4 & 22.5 \\
\hline \multirow[t]{2}{*}{ Specific surface area $S\left[\mathrm{~m}^{2} / \mathrm{kg}\right]$} & $39000-239000$ & $15000-481000$ & $1000-223000$ \\
\hline & 110125 & 154786 & 93167 \\
\hline \multirow[t]{2}{*}{ Natural water content $w$ [\%] } & $31-396$ & $11-67$ & $2-57$ \\
\hline & 126 & 28.2 & 23.5 \\
\hline \multirow{2}{*}{ Liquid limit $w_{L}[\%]$} & $46-114$ & $24-104$ & $45-59$ \\
\hline & 70.6 & 50.8 & 51.8 \\
\hline \multirow[t]{2}{*}{ Plastic limit $w_{p}[\%]$} & $22-85$ & $13-49$ & $22-30$ \\
\hline & 38 & 25.5 & 26 \\
\hline \multirow[t]{2}{*}{ Plasticity index $I_{P}[\%]$} & $24-47$ & $9-70$ & $23-29$ \\
\hline & 35.1 & 24.8 & 25.8 \\
\hline \multirow{2}{*}{$\begin{array}{l}\text { Degree of humidity (water saturation coefficient) } \mathrm{K}_{W} \\
{[-]}\end{array}$} & $0.97-1$ & $0.35-1$ & $0.96-1$ \\
\hline & 0.99 & 0.84 & 0.99 \\
\hline \multirow[t]{2}{*}{ One-axial strength $\sigma[\mathrm{MPa}]$} & $0.000016-0.0029$ & $0.0006-0.0472$ & $0.0005-0.908$ \\
\hline & 0.000441 & 0.00616 & 0.232183 \\
\hline \multirow[t]{2}{*}{ Maximum (peak) shear stress $\tau_{\max }[\mathrm{MPa}]$} & $0.00001-0.0012$ & $0.0003-0.0116$ & $0.0006-0.0226$ \\
\hline & 0.000213 & 0.00224 & 0.006625 \\
\hline \multirow[t]{2}{*}{ Minimum (residual) shear stress $\tau_{\min }[\mathrm{MPa}]$} & $0.000008-0.0002$ & $0.0002-0.0034$ & $0.0003-0.0012$ \\
\hline & 0.000068 & 0.000848 & 0.00055 \\
\hline \multirow{4}{*}{$\begin{array}{l}\text { Plastic strength (resistance to cone penetration) } P_{m} \\
\text { [MPa] } \\
\text { Propagation velocity of longitudinal ultrasonic waves } \\
V_{P}[\mathrm{~m} / \mathrm{s}]\end{array}$} & $0.00002-0.0042$ & $0.001-0.0871$ & $0.0025-0.0664$ \\
\hline & 0.000701 & 0.013296 & 0.0247 \\
\hline & $689-1647$ & $607-1870$ & $838-1323$ \\
\hline & 1384 & 1055 & 1119.3 \\
\hline
\end{tabular}

the sediment, but also from depositional conditions. Soils with a laminar microstructure have a least variable $w / w_{L}$ relationship and liquid limit, genetically representing marine and lake clays. The degree of diagenesis in such soils varies from medium to high, which generally depends on compaction related to sedimentary conditions and postsedimentary alternations of the sediment.

A commonly known relationship was observed between porosity and water content, according to which the increase of porosity is proportional to the increase of water content in the soil (Figure 7). Analysis of the graphs in relation to microstructure types shows that the largest increase and the highest values are observed in soils with a honeycomb microstructure, and the lowest values are noted in soils with a laminar microstructure. Soils with a matrix microstructure attain medium values and the increase of the relationship is also intermediate.

The analysed soils are characterised by increase of one-axial strength with decrease of porosity (Figure 8). This is also a commonly known relationship, but another relationship may also be observed with regard to microstructure types. The highest one-axial strength and lowest porosity have soils with a laminar microstructure, whereas soils with a honeycomb microstructure are characterised by a very low uniaxial strength at very high val- 


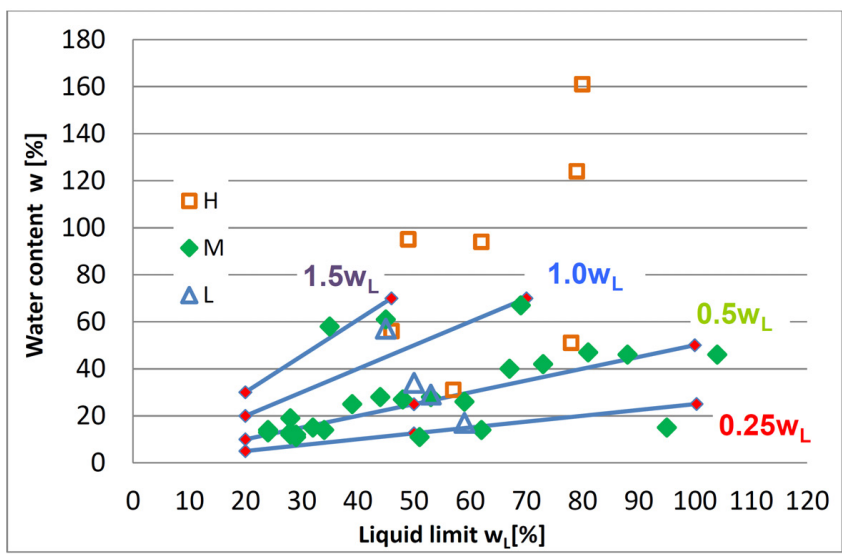

Figure 6: Chart showing the correlation between soil water content $w$ to the liquid limit $w_{L}$. See Figure 1 for the comparison of three types microstructures: $\mathrm{H}$ - honeycomb, $\mathrm{M}$ - matrix, L - laminar

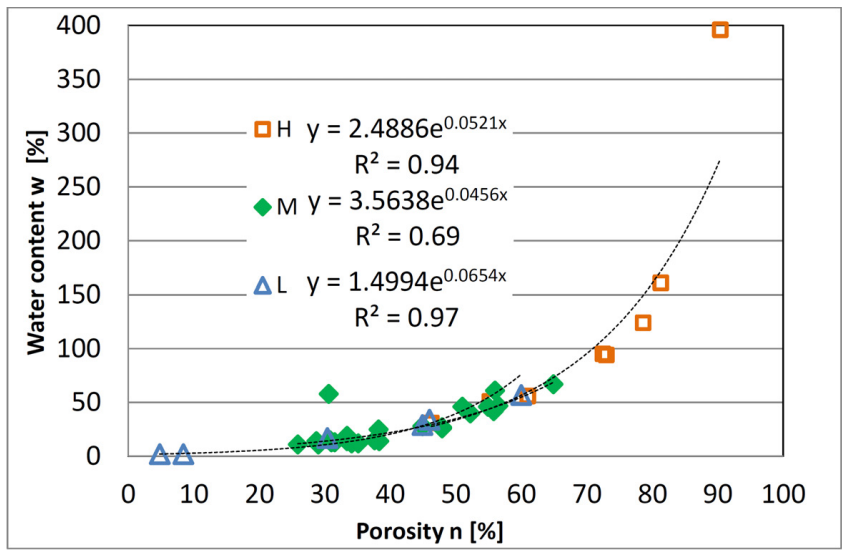

Figure 7: Chart showing the correlation between soil water content $w$ to porosity $n$. See Figure 1 for the comparison of three types microstructures: $\mathrm{H}$ - honeycomb, $\mathrm{M}$ - matrix, $\mathrm{L}$ - laminar

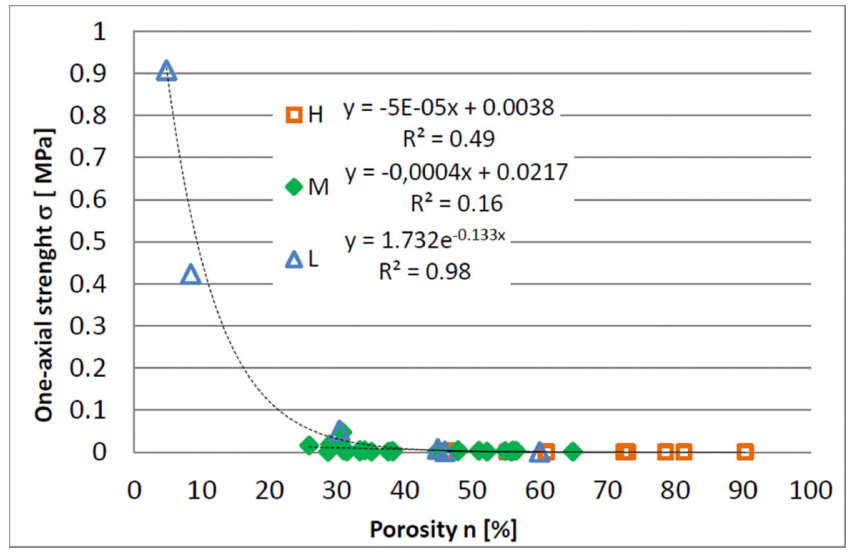

Figure 8: Chart showing the correlation between one-axial strength $\sigma$ to porosity $n$. See Figure 1 for the comparison of three types microstructures: $\mathrm{H}$ - honeycomb, $\mathrm{M}$ - matrix, $\mathrm{L}$ - laminar ues of porosity. Soils with a matrix microstructure attain intermediate values.

\section{Discussion}

Since many years scientists and practitioners have drawn much interest on the relationship between soil structure described at various levels of precision, particularly at the micro level, and the sedimentary and diagenetic processes. It is a crucial issue in geological-engineering practice to predict the influence of environment change on variable soil parameters resulting from microstructure transformations. For example, Kirkpatrick and Rennie [60] have conducted some of the first studies on microstructure transformation during the consolidation process. They concluded that it mainly depends on the conditions, in which the consolidation process takes place. During isotropic consolidation, the clay particles did not undergo reorientation and remained randomly distributed. The only factor that had changed was the degree of packing. In turn, anisotropic consolidation caused strong parallel orientation of the particles, which became arranged with their planes perpendicular to the direction of the consolidating force. The behaviour of the particle pattern in isotropic consolidation conditions should be linked with the matrix microstructure. The degree of consolidation and its duration cause only a variable degree of packing of the structural elements of soils with such microstructure. In consequence, such soils have variable geological-engineering properties, as indicated by the performed investigations (Figure 6-8). In turn, during anisotropic consolidation, the parallel pattern of particles should be linked with a laminar microstructure, and its packing would thus depend on the value of the consolidating force and the duration of its effect. Therefore, soils with a laminar microstructure have a relatively wide range of parameter values, from low to medium porosity and water content, and from high to medium strength, as shown in Figure 6-8.

Taking into account the physical and chemical conditions of sedimentation, Moon [61] discussed two cases of clay particle arrangement: 1) for flocculated particles, and 2) for dispersed particles. Fresh clay was more oriented in the case of dispersed particles than in the case of flocculated particles. Therefore, the flocculated arrangement is characterised by higher porosity. The arrangements analysed in this paper are strictly correlated with the honeycomb microstructure, which occurs in young and unconsolidated soils. Comparison of the performed investigations with particle arrangement allows to draw a conclu- 
sion that soil properties depend on the type of microstructure. The highest values of porosity and water content occur in soils with a honeycomb microstructure composed of flocculated particles, whereas soils with a honeycomb microstructure composed of dispersed particles have much lower values of these parameters. The wide range of parameter values observed in soils with a honeycomb microstructure points to such origin (Table 2, Figure 3 and Figure 7). Further studies of Moon [61] have indicated that dispersed clay particles underwent compaction and their orientation was almost parallel after the consolidation process. In the case of flocculated particles, the degree of compaction was much lower and their orientation less distinct. Such case shows that the consolidated sediments were transformed into soils with a laminar microstructure, which depending on the sedimentary conditions had a higher (dispersed sediment) and lower (flocculated sediment) degree of packing of the structural elements. The described processes indicate a strong link between the physical and chemical sedimentary conditions and the engineering properties of soils and their microstructure.

Barden [12] summed up numerous aspects of studies on the clay structure. He concluded that the electrochemical environment, in which sedimentation of clay particles occurs, plays the most important role in the formation of the clay structure. In turn, changes resulting from overburden lead to the destruction of the primary structure and creation of a privileged particle orientation. In some cases, the effect of chemical and physical rock weathering may lead to subsequent transformations of the structure, which will alter the effects caused by sedimentary and consolidation processes. Barden's [12] investigations show that geological-engineering properties of soils are the sum of processes taking place during sedimentation, consolidation and weathering. The same refers to the soil microstructure, which is the resultant of these processes. The performed studies and the obtained relationships, in which soil properties and their microstructures form not separated but rather overlapping sets, perfectly illustrate the evolution from sediment formation through postsedimentary transformations to weathering linked with environmental conditions (Table 2 and 3, Figure 6-8).

Particularly interesting are studies of submarine clays (composed of smectite and illite), which illustrate the relationship between structure and porosity [23]. This example shows the course of the process from the beginning of clay particles deposition on the bottom of the sedimentary basin to an initially consolidated sediment. Changes of clay microstructure were observed with regard to physical parameters during the consolidation process. The studies presented herein confirm that young soils with a sim- ilar mineral composition of the clay fraction have a honeycomb microstructure with the highest porosity and water content (Figure 4 and Figure 5). Subsequent condensation stages may lead to transformation of the honeycomb microstructure into a laminar microstructure, and the process is linked with changes in porosity and water content (Figure 7).

\section{Summary}

Summing up this discussion on the relationships between the origin, diagenesis, weathering, and microstructure, and the behaviour of clay soils, it has to be emphasised that earlier studies have drawn attention only to some aspects of these relationships or had a qualitative approach (e.g. [21, 62]). A quantitative approach to these relationships was first presented by Sokolov [63] and compiled recently by Kaczyński [64]. The performed investigations have confirmed and quantitatively elaborated strict relationships between all these properties.

The following conclusions can be drawn from the study:

1. detailed investigations performed on the basis of SEM image analysis have supplemented the qualitative characteristics with quantitative pore space parameters of selected types of microstructure in clay soils,

2. linear and exponential correlations were used in the analysis of quantitative data, resulting in correlation relationships between the parameters with regard to the analysed microstructural types,

3. soils with a honeycomb microstructure distinctly differ from those with a laminar microstructure with regard to morphometric properties such as diameter, perimeter and surface, content of meso- and micropores, content of isometric, anisometric and fissurelike pores, and the anisotropy index,

4. soils with a matrix microstructure attain intermediate values of morphometric properties.

The performed investigations show that a detailed characteristics of the pore space is of crucial significance in solving various issues related with geologicalengineering assessment of clay soils in variable sedimentary conditions. Distinct relationships observed between the basic physical and mechanical parameters of soils and microstructure types and their pore space confirm the importance of these relationships in basic studies and in engineering practice. 


\section{References}

[1] Grabowska-Olszewska B., Osipov V. I., Sokolov V. N., Atlas of the microstructure of clay soils, Państwowe Wydawnictwo Naukowe, Warszawa, 1984

[2] Mitchell J. K., Fundamentals of Soil Behavior. John Wiley \& Sons, Inc., New York, Chichester, Brisbane, Toronto, Singapore, 1 st ed., 1976, 2 nd ed., 1993

[3] Gillott J. E., Clay in engineering geology. Elsevier, 1987

[4] Bennett R. H., Hulbert M. H., Clay microstructure. International Human Resources Development Corporation. Boston, Houston, London, 1986

[5] Romero E., Simms P. H., Microstructure Investigation in Unsaturated Soils: A Review with Special Attention to Contribution of Mercury Intrusion Porosimetry and Environmental Scanning Electron Microscopy. Geotechnical and Geological Engineering, 2008, 26, 6, 705-727, DOI 10.1007/s10706-008-9204-5

[6] Terzaghi K., Erdbaumechanik auf bodenphysikalischer grundlage. Leipzig und Wien, Franze Dutike, 1925

[7] Goldschmidt V.M., Undersokelser over lersedimenter, Nordisk Jordbrugs forskuing, 1926, 4-7, 435-445

[8] Casagrande A., The structure of clay and its importance in foundation engineering. Journal of the Boston Society of Civil Engineers, 1932, 19(4), 168-209

[9] Lambe T. W., The structure of inorganic soil. Proceedings of the American Society of Civil Engineers, 1953, 79: pp. 1-49.

[10] Rosenqvist I. T., Physico-chemical properties of soils: Soil-water system. Journal of the Soil Mechanics and Foundation Division. Proceedings of the American Society of Civil Engineers, 1959, 85, 31-53

[11] Sloane, R. I., Kell T. R., The fabric of mechanically compacted kaolin. Clays and Clay Minerals, 1966, 14, 289-296

[12] Barden L., Theme 2, Macro- and microstructure of soils. Proceedings of the International Symposium on Soil Structure, Gothenburg, Sweden. Swedish Geotechnical Society. Stockholm, 1973

[13] Pusch R., Clay microstructure. A study of the microstructure of soft clays with special reference to their physical properties. The National Swedish Institute for Building Research. 1970, Document D8. Stockholm: $76 \mathrm{p}$.

[14] Sergeyev Y. M., Grabowska-Olszewska B., Osipov V. I., Sokolov V. N., Kolomenski Y. N., The classification of microstructures of clay soils. Journal of Microscopy, 1980, 120, 237-260

[15] Lambe T. W., The structure of compacted clay. Journal of the Soil Mechanics and Foundation Division. Proceedings of the American Society of Civil Engineers, 1958, 84: 1-34

[16] Seed H. B., Chan C. J., Structure and strength characteristics of compacted clays. Journal of the Soil Mechanics and Foundation Division. Proceedings of the American Society of Civil Engineers, 1959, 85, 87-128

[17] Barden L., Sides G. R., Engineering behavior and structure of compacted clay. Journal of the Soil Mechanics and Foundation Division. Proceedings of the American Society of Civil Engineers, 1970, 96, 1171-1200

[18] Cabrera J. G., Smalley I. J., Engineering behavior and structure of compacted clay. Discussion and reply. Journal of the Soil Mechanics and Foundation Division. Proceedings of the American Society of Civil Engineers, 1971, 97, 802-805

[19] Yong R. N., Sheeran D. E., Fabric unit interaction and soil behavior. Proceedings of the International Symposium on Soil Structure.
Gothenburg, Sweden, 1973, 176-183

[20] Collins K., McGown A., The form and function of microfabric features in a variety of natural soils. Geotéchnique, 1974, 24, 223 254

[21] Gillott J. E., Relationships between origin and microstructure of rocks and soils to engineering behaviour. Bulletin of the International Association of Engineering Geology, 1975, 11, 77-82

[22] Grabowska-Olszewska B., SEM analysis of microstructures of loesses deposits. Bulletin of the International Association of Engineering Geology, 1975, 11, 45-48

[23] Bennett R. H., Bryant W. R., Keller G. H., Clay fabric of selected submarine sediments. Fundamental properties and models. Journal of Sedimentary Petrology, 1981, 51, 217-232

[24] Grabowska-Olszewska B., Microstructural sensitivity of loesses. Bulletin of the Polish Academy of Science, Earth Science, 1982, 30, 181-188

[25] Veniale F., The role of Microfabric in Clay Soil Stability. Miner. Petrogr. Acta, 1985, 29-A, 1001-119

[26] Bryant W. R., Bennett R. H., Burkett P. J., Rack F. R., Microfabric and Physical Properties Characteristics of Consolidated Clay Section: ODP Site 697, Weddell Sea. In: Microstructure of FineGrained Sediments. From Mud to Shale (red. R. H. Bennet, W. R. Bryant, M. H. Hulbert). Springer-Verlag. New York, Berlin, Heidelberg, London, Paris, Tokyo, Hong Kong, Barcelona, 1991, 73-92

[27] Guorui G., Application of Microstructure Classification of Marine Sediment to Engineering Geological Evaluation. In: Microstructure of Fine-Grained Sediments. From Mud to Shale (red. R. H. Bennet, W. R. Bryant, M. H. Hulbert). Springer-Verlag. New York, Berlin, Heidelberg, London, Paris, Tokyo, Hong Kong, Barcelona, 1991, 531-537

[28] Pamukcu S., Tuncan M., Influence of Some Physicochemical Activities on Mechanical Behavior of Clays. W: Microstructure of Fine-Grained Sediments. From Mud to Shale (red. R. H. Bennet, W. R. Bryant, M. H. Hulbert). Springer-Verlag. New York, Berlin, Heidelberg, London, Paris, Tokyo, Hong Kong, Barcelona, 1991, 241-253

[29] Baker J. C., Grabowska-Olszewska B., Uwins P. J. R., ESEM study of osmotic swelling of bentonite from Radzionkow (Poland). Applied Clay Science, 1995, 9, 465-469

[30] Bai X., Smart P., Change in microstructure of kaolin in consolidation and undrained shear. Geotéchnique, 1997, 47, 1009-1017

[31] Cotecchia F., Chandler R. J., The influence of structure on the pre-failure behaviour of a natural clay. Geotéchnique, 1997, 47, 523-544

[32] Kaczyński R., Grabowska-Olszewska B., Soil mechanics of the potentially expansive clays in Poland. Applied Clay Science, 1997, 11, 337-355

[33] Pusch R., Schomburg J., Impact of microstructure on the hydraulic conductivity of undisturbed and artificially prepared smectitic clay. Engineering Geology, 1999, 54, 167-172

[34] Kaczyński R., Permeability, swelling and microstructure of Pliocene clays from Warsaw. In: Clay Science for Engineering (Eds K. Adachi, I. M. Fukue). A.A. Balkema. Rotterdam, Brookfield, 2001, 281-284

[35] Yong R. N., Influence of microstructural features on water, ion diffusion and transport in clay soils. Applied Clay Science, 2003, 23, 3-13

[36] Schmitz R. M., Schroeder C., Charlier R., Influence of microstructure on geotechnical properties of clays. Unsaturated Soils: Experimental Studies, 93, 89-100. Springer Berlin Heidelberg, 2005 
[37] Gratchev I. B., Sassa K., Osipov V. I., Sokolov V. N., The liquefaction of clayey soils under cyclic loading. Engineering Geology, 2006, 86, 70-84

[38] Kaczyński R., Trzciński J., The physical-mechanical and structural properties of boulder clays of the Vistula Glaciation in the area of Poland. Geological Quarterly, 1992, 36(4), 481-508

[39] Trzciński J., Qualitative and quantitative analysis of microstructures in Polish glacial tills with respect to their age. Geological Quarterly, 1995, 39(3), 403-422

[40] Kaczyński R., Trzciński J., Microstructural nonhomogeneity of glacial tills. Visnyk Lviv Univ. Ser. Mech. Math., 1999, 55, 152-157

[41] Katti D. R., Shanmugasundaram V., Influence of swelling on the microstructure of expansive clays. Canadian Geotechnical Journal, 2001, 38, 175-182

[42] Sivakumar V., Doran I. G., Graham J., Particle orientation and its influence on the mechanical behaviour of isotropically consolidated reconstituted clay. Engineering Geology, 2002, 66, 197-209

[43] Al-Mukhtar M, Khattab S., Alcover Jean-Francois, Microstructure and geotechnical properties of lime-treated expansive clayey soil, Engineering Geology, 2012, V. 139-140, pp. 17-27

[44] Zhang T., Liu S., Cai G., Anand J., Puppala A. J., Experimental investigation of thermal and mechanical properties of lignin treated silt. Engineering Geology, 2015, 196, 1-11

[45] Zhang T, Cai G., Liu S., Assessment of mechanical properties in recycled lignin-stabilized silty soil as base fill material. Journal of Cleaner Production, 2018a, 172, 1788-1799

[46] Zhang T., Cai G., Liu S., Application of Lignin-Stabilized Silty Soil in Highway Subgrade: A Macroscale Laboratory Study, Journal of Materials in Civil Engineering, ASCE, 2018b, 30(4), 1-16)

[47] Liu X., Buzzi O., Yuan S., Mendes J., Fityus S., Multi-scale characterization of retention and shrinkage behaviour of four Australian clayey soils. Canadian Geotechnical Journal, 2016, 53 (5), 854870

[48] Rosone M., Celauro C., Ferrari A., Microstructure and shear strength evolution of a lime-treated clay for use in road construction, International Journal of Pavement Engineering, 2018, DOI: $10.1080 / 10298436.2018 .1524144$

[49] Sun W. J., Cui Y. J. Investigating the microstructure changes for silty soil during drying. Géotechnique, 2018, 68 (4), 370-373

[50] Sorby H. C., On the application of quantitative methods to the study of the structure and history of rocks. Quarterly Journal of the Geological Society of London, 1908, 64, 171-233
[51] Aylmore L. A. G., Quirk J. P., Domain or turbostratic structure of clays. Nature, 1960, 187, 1046-1048

[52] Sergeyev Y. M., Grabowska-Olszewska B., Osipov V. I., Sokolov V. N., Types of the microstructures of clayey soils. Proceedings of the III International Congress I.A.E.G., 4-8 September, 1978, 1, 319-327

[53] Czapowskij E. G., Laboratornyje raboty po gruntowiedieniu i miechanikie gruntow. Niedra, 1975

[54] Szukin E. D., Biessonow A. I., Paranskij S. A., Miechaniczeskije ispytania katalizatorow i sorbientow. Niedra 1971

[55] Tovey N. K., Wong W. K. The Preparation of Soil and Other Geological Material for the SEM. International Symposium of Soil Structure, Gothenburg, 1973, 59-69

[56] Smart P., Tovey K. Electron microscopy of soils and sediments: techniques. Clarendom Press, Oxford, 1982

[57] Trzciński J., Combined SEM and computerized image analysis of clay soils microstructure: technique \& application. In: Jardine, R. J., Potts, D. M., Higgins, K. G. eds., Advances in geotechnical engineering: The Skempton conference, Thomas Telford, London, 2004, 654-666

[58] Sokolov V. N., Yurkovets D. I., Razgulina O. V., Stiman (Structural Image analysis): a software for quantitative morphological analysis of structures by their images (User's manual. Version 2.0). Laboratory of Electron Microscopy, Moscow State University, Moscow, 2002

[59] Skempton A. W. First-Time Slides in Over-Consolidated Clays, Géotechnique, 1970, 20, 3, 320-324

[60] Kirkpatrick W. M., Rennie I. S. Directional properties of consolidated kaolin. Geotéchnique, 1972, 22, 166-169

[61] Moon C. F. The microstructure of clay sediments. Earth-Science Reviews, 1972, 8, 303-321

[62] Osipov V. I., Sokolov V. N. Relation between the microstructure of clay soils and their origin and degree of compaction. Bulletin of the International Association of Engineering Geology, 1978, $18,73-81$

[63] Sokolov V.N. Engineering-geological classification of clay microstructures. Proc. of 6th International IAEG Congress, Rotterdam, 1990, 753-760. A.A. Balkema.

[64] Kaczyński R. Warunki geologiczno-inżynierskie na obszarze Polski. Państwowy Instytut Geologiczny - PIG. Wyd. 1. Warszawa. 2017 